\title{
Medical Informatics in Indonesia: Importance, Development, and Future Directions
}

\author{
Seng Hansun \\ Universitas Multimedia Nusantara, Jl. Scientia Boulevard, Tangerang, Indonesia
}

\begin{abstract}
Medical Informatics (MI) is an emerging multidisciplinary study in academic fields. Also known as 'Health Informatics,' this study combines three different well-known fields; Information Systems (IS), Computer Science (CS), and Health Science (HS). MI is crucial because it could help in bridging the gap that is commonly found in conventional Healthcare services with the usage of Information Technology (IT). However, despite its vital role, the development of MI in Indonesia is still not satisfactory. Therefore, in this paper, the importance of $\mathrm{MI}$ as an academic discipline will be briefly discussed, followed by the description of MI development in Indonesia, and some suggestions for its future development.
\end{abstract}

Keywords - Informatics, Health Science, Indonesia, Information Systems, Medical Informatics.

\section{Introduction}

Medical Informatics (MI) is an emerging academic discipline that is essential for its role and contribution to improve Healthcare services by employing Information Technology. Also known as Health Informatics, MI consist of different kinds of fields, namely Computer Science or Informatics, Decision Science, Statistics, Medical Science, etc. [1].

Also known as Health Informatics, MI consist of different kinds of fields, namely Computer Science or Informatics, Decision Science, Statistics, Medical

DOI: 10.18421/TEM101-10

https://doi.org/10.18421/TEM101-10

Corresponding author: Seng Hansun,

Universitas Multimedia Nusantara, Jl. Scientia Boulevard,

Tangerang, Indonesia.

Email: seng.hansun@lecturer.umn.ac.id

Received: 15 August 2020.

Revised: 05 January 2021.

Accepted: 11 January 2021.

Published: 27 February 2021.

(c) BY-NC-ND (C) 2021 Seng Hansun; published by UIKTEN. This work is licensed under the Creative Commons Attribution-NonCommercial-NoDerivs 4.0 License.

The article is published with Open Access at www.temjournal.com
Science, etc. [1]. However, the three most prominent fields in MI are Information Systems (IS), Computer Science (CS), and Health or Medical Science (HS).

As a relatively 'young' discipline that emerge in 1970s, there has been changes, variations, and development of MI that leads to different definitions, concepts, and sub-disciplines. AMIA (American Medical Informatics Association) for example, tends to use the terms of biomedical informatics and healthcare informatics rather than medical informatics, which is used as a parallel term to other subareas, such as nursing informatics and dental informatics [2]. Other researchers have adopted the terms and definition given by AMIA, such as Sweeney [3], Valenta et al. [4], and Cummings et al. [5]. Meanwhile, the others prefer to use the medical informatics term as can be found in the works of Mihalas et al. [6], Collen and Shortliffe [1], and Wyatt and Liu [7]. Here, throughout this paper we used the latter term, i.e., the Medical Informatics (MI).

In the next section, we will stress out the importance of MI as an academic discipline. Moreover, the description of MI development in Indonesia will be given in the following sections together with some solution and future directions for MI development in Indonesia.

\section{Importance of Medical Informatics}

Medical Informatics (MI) is important for its role and contribution to improve Healthcare services by employing Information Technology (IT). Its importance can be deducted from its nature as a multidisciplinary study, its contribution to society, and its future directions that open up many possibilities.

The first factor that shows MI's importance is its nature as a multidisciplinary study. Kim and Delen [8] define MI as a multidisciplinary field that implements IT to medical domain so that it could improve healthcare services and medicine. As a cross-section discipline of three big fields, MI could take advantage of each field and apply them to solve problems faced by other fields. As claimed by Cassell [9] for example, by using the help of a Computer Science programmer to build specialized software, a clinician (Health 
Science practitioner) could provide answers to complex questions about patients' conditions. Another piece of research by Ahmed et al. [10] has shown the benefit of a self-management support system to enhance the life quality of asthma patients.

The second factor that shows the importance of MI is its contribution to society. Much research has been done by notable researchers to tackle various problems by using MI's approach. Hughes et al. [11] have presented a method to classify medical texts by using Convolutional Neural Networks (CNN). Jagannatha and $\mathrm{Yu}$ [12] have explored the usage of Recurrent Neural Networks (RNN) for medical event detection. Jayawardanu and Hansun [13] have also designed an expert system for cataract detection using C4.5 and Leonardo et al. [14] have built a fuzzy AHP based expert system for detection of pulmonary tuberculosis disease. Furthermore, a Could-IoT (a cloud-based Internet of Thing) based sensing service to monitor the health of elderly people has also been produced by Neagu et al. [15], while Motulsky et al. [16] have studied and reported the usage of mobile devices for inpatient rounding and handoffs. Some researchers even give their focus to the development of MI's education, as can be found in the research of Saranto et al. [17], Valenta et al. [4], Cummings et al. [5], and Jaspers et al. [18]. All of these show the significant contribution offered by MI to the health of global society.

The last highlighted factor of MI's importance is its future directions. As an emerging discipline, MI could open up many possibilities and discoveries. Three main tracks of future directions which may be explored are (1) Education and management perspectives, that focus to adapt MI's learning and teaching materials together with its management practices in health facilities; (2) Software and data analytics, that include all the software development and data analysis results using various algorithms in the CS field; and (3) Hardware and related technologies, that incorporate all devices' utilization in the MI field including the related technologies being used. Moreover, MI also brings up the possibilities for the development of new subfields, such as Clinical Informatics, Medical Imaging Informatics, and Pathology Informatics.

\section{MI Development in Indonesia}

Even though MI has gained considerable attention worldwide from its importance as an academic discipline, the development of MI in Indonesia is still not satisfactory. There are only a few higher education institutions in Indonesia that offer MI course; the research publication numbers in MI are relatively low compared to the number of research publications in its parent domains; and there are only few Indonesia periodicals that have focus in this field.

The low numbers of higher education institutions in Indonesia that offer MI as one of their courses have become its main drawback. There are more than 4,500 higher education institutions in Indonesia, but less than one percent of them have focus in MI. Moreover, many of them do not offer MI as a major, but rather as a minor or specialization subject in their respective programs. For example, Universitas Indonesia (UI) places $\mathrm{MI}$ as one of its 15 specializations in Public Health Master Program. Universitas Islam Indonesia (UII) offers MI as one of its minors in the Informatics Master Program. Universitas Gadjah Mada (UGM) also offers MI in its Public Health Master Program, specifically in the Health Management Information System Program. Universitas Pelita Harapan (UPH) offers MI at Undergraduate degree level but only as a specialization in its Informatics department. On the other hand, at least five different universities in Australia offer MI as a full course program, such as the Swinburne University of Technology, University of Wollongong, the University of Tasmania, Griffith University, and La Trobe University. From the mentioned examples, it can be clearly seen that MI has yet to become a major academic discipline in Indonesia's higher education institutions.

Another factor shows the unsatisfactory and slow development of MI in Indonesia is the low number of research publications compared to its parent domains, such as Information System (IS), Computer Science (CS) or Informatics (IF), and Health Science (HS). According to the ScimagoJR, one of the major publication-ranking systems, there is only 247 published documents in Health Informatics area from Indonesian authors during 2018-2019 [19]. Meanwhile, during the same period, there are 3,088 published documents in Medicine (HS) and 5,682 published documents in Computer Science (IF and IS) from Indonesian authors. So, there are significant differences in the publication numbers; it takes only around $8 \%$ of Medicine's publication, $4 \%$ of Computer Science's, and nearly $2 \%$ of both Medicine and Computer Science's publications. Figure 1 depicts the bubble chart that relates the number of published documents in the Medicine field (where Health Informatics located) versus its H Index (a metric measuring the productivity and citations impact of a publication) for Indonesian authors during 2018-2019. 


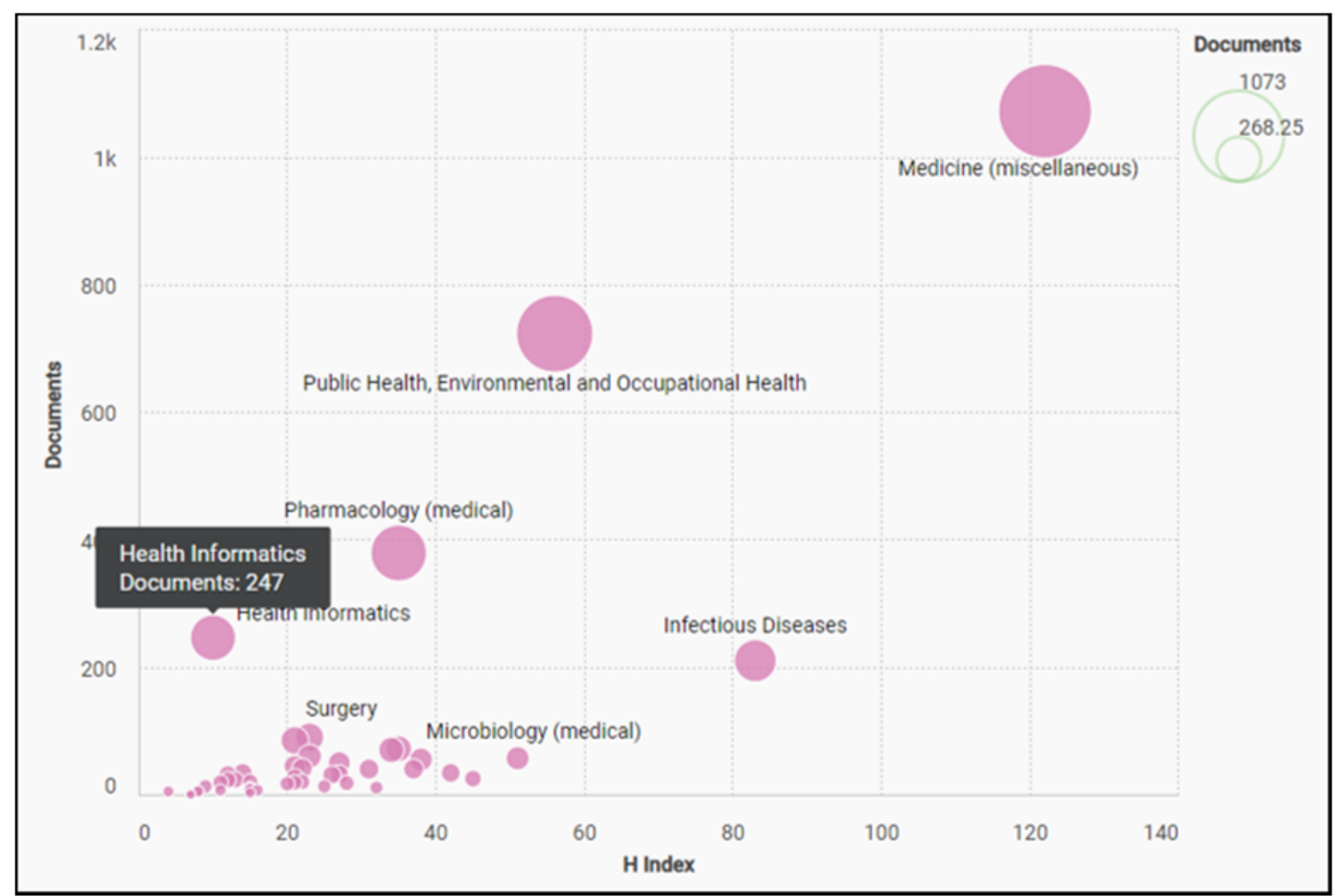

Figure 1. Subject bubble chart in Medicine field for Indonesian authors during 2018-2019 [19]

Lastly, there is a low number of academic journals from Indonesia publishers that give their focus on MI field. Out of 304 registered journals in SINTA (Science and Citation Index) [20] from the Health category, hardly $5 \%$ of them have related focuses and scopes in MI. Many of them still give broader focuses that fall in Public Health categories, such as Hospital Management, Health Policy, and Clinical Teaching. In fact, there are only two journals that clearly state their focuses in MI, i.e., the JEEEMI (e-ISSN 26568632) and the IJEEEMI (e-ISSN 2656-8624). Both of them are published by Health Polytechnic Ministry of Health of Surabaya and Indonesian Electromedical Association (Ikatan Elektromedis Indonesia, IKATEMI) and had their inaugural editions in July and August 2019 respectively. However, since they are relatively new published journals, they are not registered yet as accredited journals in SINTA.

\section{Solutions and Future Directions}

There are two possible solutions to address the unsatisfactory development of MI in Indonesia. Firstly, by founding a recognizable national organization in the MI field and secondly, by developing and implementing the MI curriculum as a major course in higher education institutions.

The first suggested solution is by founding a recognizable national organization in the MI field. Actually, there are several international organizations in the MI field, such as the AMIA (American Medical Informatics Association), the HIMSS (Healthcare Information and Management Systems Society), and the IMIA (International Medical Informatics Association). IMIA even has a regional represented association called the APAMI (Asia Pacific Association for Medical Informatics), where
Indonesia is one of its corresponding member countries [21]. However, the activities and contributions from Indonesia are hardly ever heard. Therefore, it would be better to have a nation-wide government-supported organization that could gather all Indonesian scientists and researchers from different fields related to MI and actively organize various events that could positively contribute to the development of MI in Indonesia.

Another suggestion that could be given is to develop a standardized curriculum for MI in Indonesia. The curriculum should consider MI as a major discipline and should be assessed by acknowledgeable organizations and researchers in the MI field and supported by the Indonesian Government, specifically from the Ministry of Health and the Ministry of Education and Culture. By having a standardized curriculum, a higher chance of successful implementation of MI in higher education institutions is likely to be achieved. By having a higher number of higher education institutions offering MI, a greater number of students and researchers could be gathered and work productively together toward a better future development of MI in Indonesia.

\section{Conclusion}

In conclusion, $\mathrm{MI}$ as an emerging academic discipline is essential due to its nature as a multidisciplinary study, its contribution through education and research breakthroughs, and its future directions that open up many possibilities and discoveries. However, MI development in Indonesia is not progressing as expected. The low number of higher education institutions offering MI, the low number of research publications, and the low number of Indonesia periodicals focusing on MI are some 
indications of this matter. Two possible solutions to handle this issue are by founding a recognized national organization and by developing and implementing MI curriculum as a major course in higher education institutions in Indonesia.

\section{References}

[1]. Collen, M. F., \& Shortliffe, E. H. (2015). The creation of a new discipline. In The History of Medical Informatics in the United States (pp. 75-120). Springer, London. https://doi.org/10.1007/978-1-4471-6732-7_2.

[2]. Kulikowski, C. A., Shortliffe, E. H., Currie, L. M., Elkin, P. L., Hunter, L. E., Johnson, T. R., ... \& Williamson, J. J. (2012). AMIA Board white paper: definition of biomedical informatics and specification of core competencies for graduate education in the discipline. Journal of the American Medical Informatics Association, 19(6), 931-938. https://doi.org/10.1136/amiajnl-2012-001053.

[3]. Sweeney, J. (2017). Healthcare informatics. On-Line Journal of Nursing Informatics, 21(1).

[4]. Valenta, A. L., Berner, E. S., Boren, S. A., Deckard, G. J., Eldredge, C., Fridsma, D. B., ... \& Johnson, S. B. (2018). AMIA Board White Paper: AMIA 2017 core competencies for applied health informatics education at the master's degree level. Journal of the American Medical Informatics Association, 25(12), 1657-1668. https://doi.org/10.1093/jamia/ocy132.

[5]. Cummings, E., Whetton, S., \& Mather, C. (2017). Integrating Health Informatics Into Australian Higher Education Health Profession Curricula. In Health Professionals' Education in the Age of Clinical Information Systems, Mobile Computing and Social Networks (pp. 323-343). Academic Press. https://doi.org/10.1016/B978-0-12-805362-1.00016-4.

[6]. Mihalas, G., Zvarova, J., Kulikowski, C., Ball, M., van Bemmel, J., Hasman, A., ... \& Barber, B. (2014). History of medical informatics in Europe-a short review by different approach. Acta Informatica Medica, 22(1), 6. https://doi.org/10.5455/aim.2014.22.6-10.

[7]. Wyatt, J. C., \& Liu, J. L. Y. (2002). Basic concepts in medical informatics. Journal of Epidemiology \& Community Health, 56(11), 808-812. https://doi.org/10.1136/jech.56.11.808.

[8]. Kim, Y. M., \& Delen, D. (2018). Medical informatics research trend analysis: A text mining approach. Health informatics journal, 24(4), 432-452. https://doi.org/10.1177/1460458216678443.

[9]. Cassell, A. (2016). The Role of Informatics and Electronic Health Record in Current Medical Practice: What Are the Benefits of Medical Informatics to the Clinician?. In Resident's Handbook of Medical Quality and Safety (pp. 29-32). Springer, Cham. https://doi.org/10.1007/978-3-319-24190-6 5.

[10]. Ahmed, S., Ernst, P., Bartlett, S. J., Valois, M. F., Zaihra, T., Paré, G., ... \& Tamblyn, R. (2016). The effectiveness of web-based asthma self-management system, My Asthma Portal (MAP): a pilot randomized controlled trial. Journal of medical Internet research, 18(12), e313.
[11]. Hughes, M., Li, I., Kotoulas, S., \& Suzumura, T. (2017). Medical text classification using convolutional neural networks. Stud Health Technol Inform, 235, 246-50. https://doi.org/10.3233/978-1-61499-753-5-246.

[12]. Jagannatha, A. N., \& Yu, H. (2016, June). Bidirectional RNN for medical event detection in electronic health records. In Proceedings of the conference. Association for Computational Linguistics. North American Chapter. Meeting (Vol. 2016, p. 473). NIH Public Access. $10.18653 / \mathrm{v} 1 / \mathrm{N} 16-1056$.

[13]. Jayawardanu, I. H. W., \& Hansun, S. (2015). Rancang Bangun Sistem Pakar Untuk Deteksi Dini Katarak Menggunakan Algoritma C4. 5. Ultima Computing: Jurnal Sistem Komputer, 7(2), 48-58. https://doi.org/10.31937/sk.v7i2.232.

[14]. Leonardo, J., Young, J. C., \& Hansun, S. (2019). Early Detection of Pulmonary Tuberculosis Disease With Fuzzy Ahp Expert System. Compusoft, 8(10), 3444-3447.

[15]. Neagu, G., Preda, Ş., Stanciu, A., \& Florian, V. (2017, June). A Cloud-IoT based sensing service for health monitoring. In 2017 E-Health and Bioengineering Conference (EHB) (pp. 53-56). IEEE. https://doi.org/10.1109/EHB.2017.7995359.

[16]. Motulsky, A., Wong, J., Cordeau, J. P., Pomalaza, J., Barkun, J., \& Tamblyn, R. (2017). Using mobile devices for inpatient rounding and handoffs: an innovative application developed and rapidly adopted by clinicians in a pediatric hospital. Journal of the American Medical Informatics Association, 24(e1), e69-e78. https://doi.org/10.1093/jamia/ocw107.

[17]. Saranto, K., Kinnunen, U. M., Kivekäs, E., Huusko, J., \& Kuusisto-Niemi, S. (2017, August). The Guiding Role of a Paradigm in Informatics Education and Research. In ICIMTH (pp. 235-238). https://doi.org/10.3233/978-1-61499-781-8-235.

[18]. Jaspers, M. W., Mantas, J., Borycki, E., \& Hasman, A. (2017). IMIA Accreditation of Biomedical and Health Informatics Education: Current State and Future Directions. Yearbook of Medical Informatics, 26(1), 252-256. https://doi.org/10.15265/IY-2017-011.

[19]. Subject Bubble Chart. (2020). Scimago Journal \& Country Rank. Subject bubble chart 2018-2019.

Retrieved from:

https:/www.scimagojr.com/mapgen.php?maptype=bc $\&$ country $=$ ID $\& y=$ item $\& x=h$. [accessed: 10 August 2020].

[20]. Ahmadi, A. (2019). The use of Sinta (Science and Technology Index) Database to Map the Development of Literature Study in Indonesia. International Journal of Mechanical Engineering and Technology, 10(02), 918-923.

[21]. John, O., Schaper, L., Wong, C. P., Siribaddana, P., Choi, I. Y., Marcelo, A., \& Dissanayake, V. H. (2020). APAMI. Yearbook of Medical Informatics, 29(01), 281-283. $10.1055 / \mathrm{s}-0040-1701977$. 